\title{
Positioning Unit Rehabilitasi Medik sebagai Centre of Excellence di Rumah Sakit Baptis Batu
}

\section{Medical Rehabilitation Unit Positioning as a Centre of Excellence in Baptis Hospital Batu}

\author{
Evi Laksana ${ }^{1}$, Tatong Hariyanto ${ }^{2}$, Arhwinda Pusparahaju ${ }^{3}$ \\ ${ }^{1}$ Rumah Sakit Bersalin Mardi Waloeja Rampal Malang \\ ${ }^{2}$ Program Studi Magister Manajemen Rumah Sakit Fakultas Kedokteran Universitas Brawijaya Malang \\ ${ }^{3}$ Rumah Sakit Baptis Batu
}

\begin{abstract}
ABSTRAK
Rumah sakit perlu membangun produk unggulan (centre of excellence) yang dapat menarik pasien dan citra rumah sakit. Penelitian ini dilakukan untuk mengeksplorasi positioning unit rehabilitasi medi di mata pelanggan. Penelitian dilakukan pada 30 responden yang dipilih secara accidental sampling pada bulan Oktober 2013. Jumlah sampel yang diambil sebanyak 30 responden dengan menggunakan kuesioner, dengan variasi pertanyaan tertutup yang menggunakan skala Likert, serta pertanyaan terbuka sebagai instrumen. Variabel yang diukur adalah karakteristik responden dan respon terhadap positioning kualitas pelayanan rehabilitasi medik. Hasil menunjukkan karakteristik responden yang datang menggunakan fasilitas rehabilitasi medik sebagian besar berusia usia 31-35, perempuan, berasal dari dari wilayah batu, tingkat pendidikan sarjana, bekerja sebagai PNS/PPNS, dengan sumber pembiayaan terbesar dari ASKES. Dimata pelanggan menunjukkan bahwa pelayanan yang diberikan baik, ramah, cepat, tepat, serta mempunyai tingkat keberhasilan terapi yang baik, dengan fasilitas lengkap dan harga terjangkau. Unit juga sudah menjadi top of mind responden jika memerlukan pelayanan rehabilitasi medik. Hasil ini menunjukkan bahwa unit rehabilitasi medik mempunyai potensi untuk dikembangkan menjadi centre of excellence di Rumah Sakit Baptis Batu.
\end{abstract}

Kata Kunci: Produk unggulan (centre of excellence), unit rehabilitasi medik, positioning

\section{ABSTRACT}

Every hospital needs to build a center of excellence that can attract patients and raise hospital image. This research is conducted to explore medical rehabilitation unit positioning in the customers' point of view. This research was conducted on 30 respondents based on accidental sampling selection on October 2013. Samples taken were 30 respondents using questionnaire, with a variation of the closed questions using Likert scale, and open-ended questions as instruments. The variables measured were the characteristics of the respondents and the response to the positioning of medical rehabilitation service quality. The results shows the characteristics of respondents who utilize the facilities of medical rehabilitation are mostly 31-35 years of age, females, come from Batu region, hold bachelor degree, work as a civil servant/investigators, mostly are funded by Askes (civil insurance firm). In the customers' point of view, the services given are good, friendly, fast, precise, and have a good success rate of therapy, with complete facilities and affordable prices. The unit also has become respondents' top of mind if they should require medical rehabilitation services. These results indicate that the medical rehabilitation unit has the potential to be developed into a center of excellence in Baptis Hospital Batu.

Keywords: Center of excellence, medical rehabilitation unit, positioning

Jurnal Kedokteran Brawijaya, Vol. 28, Suplemen No. 1, 2014: Evi Laksana, Rumah Sakit Bersalin Mardi Waloeja Rampal Malang, JI.WR. Supratman 1 Malang, Tel.(0341)364756Email:evi.laksana@yahoo.com 


\section{PENDAHULUAN}

Rumah sakit merupakan organisasi atau institusi yang padat modal, padat teknologi, padat karya dan padat keterampilan dengan sumber daya manusia yang sangat beragam dituntut untuk dapat memberikan pelayanan yang dapat memuaskan pelanggan (1). Seiring dengan perkembangan era globalisasi, sebuah rumah sakit tidak hanya mempunyai misi sosial, tetapi juga harus mempunyai misi bisnis yang berorientasi pada keuntungan (profit oriented). Karena untuk dapat berkembang dan mampu mewujudkan program-program rumah sakit dibutuhkan dana yang bersumber dari pendapatan rumah sakit. Pendapatan rumah sakit bersumber dari jumlah pasien yang datang berobat ke rumah sakit. Oleh karena itu diperlukan strategi pemasaran yang baik, serta produk unggulan yang dapat menarik pasien untuk datang berobat.

Salah satu produk Rumah Sakit Baptis Batu (RSBB) yang dapat dijadikan unggulan adalah Rehabilitasi Medik. Di kawasan Batu dan sekitarnya belum ada rumah sakit yang menyediakan fasilitas rehabilitasi medik selengkap RSBB. Dengan tidak adanya pesaing diharapkan RSBB dapat menjadi tujuan utama serta rujukan pasien-pasien yang membutuhkan perawatan rehabilitasi medik, yang pada akhirnya rehabilitasi medik diharapkan akan menjadi centre of excellence RSBB.

Di wilayah kecamatan Batu dan Junrejo terdapat 5 rumah sakit, yaitu RS Paru Batu, RS Hasta Brata, RS dr. Etty Asharto, RS Haji Batu (IPHI), dan RS Baptis Batu. Dari kelima rumah sakit tersebut belum ada yang memiliki unit rehabilitasi medik selengkap RS Baptis Batu. RS Paru Batu hanya memiliki unit fisioterapi saja. Unit Rehabilitasi Medik di RSBB mulai beroperasi pada tahun 2005. Sebelumnya RSBB hanya mempunyai unit Fisioterapi saja, yang beroperasi mulaii tahun 1999, bersamaan dengan mulai berdirinya RSBB. Unit Fisioterapi ini memiliki pelayanan yang terbatas, terutama hanya melayani pasien-pasien yang membutuhkan terapi untuk gerak, misalnya belajar jalan. Unit Rehabilitasi Medik mempunyai pelayanan yang lebih comprehensive, dan mempunyai tujuan untuk meminimalisir kecacatan, dan meningkatkan kualitas hidup dengan berbagai penanganan, seperti terapi okupasi, terapi wicara, alat bantu ortetik prostetik, termasuk juga fisioterapi. Setiap pasien yang datang ke unit rehabilitasi medik akan ditentukan diagnosanya, untuk kemudian dibuat rencana program terapi dan target keberhasilannya (2).

Pelayanan rehabilitasi medik meliputi pencegahan, diagnosa, dan penanganan gangguan fisik dan fungsional dengan tujuan untuk mengusahakan penderita cacat agar dapat hidup mandiri semaksimal mungkin, agar dapat berguna bagi sesama (3). Melihat semakin luas dan berkembangnya pelayanan rehabilitasi medik di RSBB, diharapkan unit rehabilitasi medik dapat menjadi salah satu sumber pendapatan yang penting, sebagai centre of excellence dalam memajukan RSBB.

Data kinerja rumah sakit memperlihatkan adanya adanya perkembangan dan pertumbuhan pada tiap divisi pelayanan yang ada. Khusus untuk divisi Rehabilitas Medik tampak ada pertumbuhan rata-rata sebesar $8 \%$. Penambahan jumlah kunjungan tampak cukup signifikan pada tahun 2009, yaitu dari 5.550 pada tahun 2008 menjadi 8.932 pada tahun 2009. Kemudian pada tahuntahun berikutnya tetap terjadi peningkatan, tetapi pada tahun 2012 tampak adanya penurunan jumlah kunjungan jika dibandingkan dengan tahun 2011. Hal ini dapat disebabkan adanya kebijakan pemerintah tentang pembatasan dari PT. ASKES dan JAMKESMAS untuk melakukan kunjungan hanya ke satu dokter spesialis saja, sehingga mereka lebih mengutamakan berkunjung ke dokter spesialis utama, bukan penunjang seperti rehabilitasi medik.

Data rumah sakit juga menunjukkan adanya penurunan jumlah pasien tidak terasuransi dari tahun ke tahun, sedangkan pasien ASKES Sosial/PNS dan JAMKESMAS jumlah kunjungannya tetap tinggi. Pasien yang datang ke unit Rehabilitasi Medik sebagian besar adalah pasien ASKES Sosial/PNS dan JAMKESMAS. Hal ini menunjukkan bahwa strategi pemasaran RSBB yang tercantum dalam rencana strategi RSBB 2008-2012 untuk meningkatkan market pasien yang membayar mandiri di unit rehabilitasi medik ini belum tercapai. Untuk itu diperlukan langkahlangkah strategi pemasaran yang lebih sesuai, diantaranya adalah dengan menjadikan Unit Rehabilitasi Medik RSBB sebagai sebuah produk unggulan, sebagai sebuah centre of excellence sehingga dapat lebih dikenal masyarakat luas. Dalam menentukan langkah-langkah strategi pemasaran, kebijakan pemerintah yang baru tentang Jaminan Kesehatan Nasional perlu dipertimbangkan, karena pelayanan unit rehabilitasi medik termasuk dalam pelayanan yang pembayarannya dapat ditanggung oleh pemerintah melalui sistem Jaminan Kesehatan Nasional.

Dari data rumah sakit juga tampak adanya penurunan jumlah kunjungan yang ditangani dokter spesialis Rehabilitasi Medik, karena sejak tahun 2009 dokter spesialis Rehabilitasi Medik tersebut merangkap sebagai Direktur RSBB, sehingga banyak kegiatan, rapat-rapat dan kunjungan ke luar kota yang harus diikuti. Hal ini menyebabkan semakin sedikit pasien yang dapat ditangani oleh dokter spesialis rehabilitasi medik tersebut.

Center of excellence merupakan sebuah pusat keunggulan mengacu pada tim, fasilitas bersama atau sebuah organisasi yang menyediakan kepemimpinan, praktik terbaik, penelitian, dukungan dan atau pelatihan untuk area yang terfokus. Fokus area dalam hal ini mungkin teknologi, sebuah konsep bisnis, keterampilan atau area studi yang luas. Sebuah center of excellence dapat juga bertujuan untuk merevitalisasi inisiatif macet. Dalam sebuah organisasi, center of excellence dapat merujuk kepada sekelompok orang, departemen atau fasilitas bersama. Ini mungkin juga dikenal sebagai pusat kompetensi atau pusat kemampuan. Di sektor kesehatan, istilah ini sering ditujukan untuk pusat pelayanan kesehatan yang memberikan layanan medis yang memadai dan mudah diakses oleh pasien (4).

\section{METODE}

Penelitian ini dilakukan dengan survei pada 30 pengunjung pelayanan unit rehabilitasi medik RSBB bulan Oktober 2013. Instrumen yang digunakan berupa kuesioner, dengan variasi pertanyaan tertutup dengan skala Likert, serta pertanyaan terbuka. Variabel yang diukur adalah karakterisitik responden, pihak pengirim, alasan dikirim, kesan mutu layanan, dan usulan perbaikan pelayanan.

\section{HASIL}

Survei pada pasien di unit rehabilitasi medik RSBB digunakan sebagai dasar untuk mengetahui pandangan pengguna fasilitas terhadap unit rehabilitasi Rumah Sakit 
Baptis Batu. Dari Tabel 1 di atas tampak bahwa karakteristik responden yang datang menggunakan fasilitas rehabilitasi medik adalah usia responden terbanyak usia 31-35, sebagian besar responden adalah perempuan, asal pasien terbanyak dari wilayah Batu, tingkat pendidikan terbanyak adalah sarjana, dengan pekerjaan PNS/PPNS, dan sumber pembiayaan dari ASKES.

Tabel 1. Karakteristik responden

\begin{tabular}{|c|c|c|}
\hline No & Karakteristik Responden & Jumlah (\%) \\
\hline \multirow[t]{4}{*}{1.} & Umur Responden & \\
\hline & $19-30$ & $3 \%$ \\
\hline & $31-55$ & $55,5 \%$ \\
\hline & $56-84$ & $43,5 \%$ \\
\hline \multirow[t]{3}{*}{2.} & Gender & \\
\hline & Laki-laki & $40 \%$ \\
\hline & Perempuan & $60 \%$ \\
\hline \multirow[t]{3}{*}{3.} & Asal Responden & \\
\hline & Batu & $90 \%$ \\
\hline & Luar Batu & $10 \%$ \\
\hline \multirow[t]{5}{*}{4.} & Pendidikan Responden & \\
\hline & Tamat SD & $3 \%$ \\
\hline & Tamat SLTP & $23 \%$ \\
\hline & Tamat SLTA & $22 \%$ \\
\hline & Sarjana + & $53 \%$ \\
\hline \multirow[t]{5}{*}{5.} & Pekerjaan & \\
\hline & Swasta/Wiraswasta & $30 \%$ \\
\hline & PNS/PPNS & $54 \%$ \\
\hline & $A B R I$ & $3 \%$ \\
\hline & Tidak bekerja & $13 \%$ \\
\hline \multirow[t]{5}{*}{6.} & Sumber Pembiayaan & \\
\hline & Pribadi & $20 \%$ \\
\hline & ASKES & $67 \%$ \\
\hline & Jamkesmas & $3 \%$ \\
\hline & Asuransi Swasta & $10 \%$ \\
\hline
\end{tabular}

Identifikasi implementasi positioning unit rehabilitasi medik RSBB, bertujuan untuk menjelaskan suatu kesan atau ciri khas yang paling melekat di pikiran responden tentang unit rehabilitasi medik RSBB. Sebanyak $90 \%$ responden menyatakan RSBB merupakan rumah sakit yang pertama terlintas dalam benak ketika membutuhkan pelayanan rehabilitasi medik. Secara umum responden memberikan respon yang baik pada semua komponen positioning. Responden memberi kesan bahwa unit rehabilitasi medik RSBB sudah memberikan pelayanan yang ramah yang ditunjukkan dengan $63 \%$ menyatakan sangat baik dalam keramahan. Kecepatan pelayanan mendapatkan respon positif yang dominan. Aspek kualitas, keberhasilan terapi dan kelengkapan fasilitas, masih banyak mendapatkan respon cukup (Tabel 2 ).

Tabel 2. Positioning unit rehabilitasi medik RSBB menurut responden

\begin{tabular}{lrcr}
\hline Komponen Positioning & Cukup & Baik & Sangat Baik \\
\hline Terjangkau & $20 \%$ & $53 \%$ & $27 \%$ \\
Kelengkapan fasilitas & $26 \%$ & $47 \%$ & $27 \%$ \\
Berkualitas & $27 \%$ & $50 \%$ & $23 \%$ \\
Kecepatan pelayanan & $10 \%$ & $57 \%$ & $33 \%$ \\
Kebersihan & $23 \%$ & $40 \%$ & $37 \%$ \\
\hline
\end{tabular}

Tabel 2. Positioning unit rehabilitasi medik RSBB menurut responden (Lanjutan)

\begin{tabular}{lrrr}
\hline Komponen Positioning & Cukup & Baik & Sangat Baik \\
\hline Ketepatan pelayanan & $23 \%$ & $50 \%$ & $27 \%$ \\
Keramahan pelayanan & $7 \%$ & $30 \%$ & $63 \%$ \\
Keberhasilan terapi & $26 \%$ & $57 \%$ & $17 \%$ \\
\hline
\end{tabular}

Sumber: Kuesioner responden. Persentase menunjukkan skor 3,4,5 skala Likert

Hasil pada Tabel 2 diperkuat dengan hasil survei pertanyaan terbuka pada responden tentang rumah sakit apa yang pertama kali terlintas di benak responden apabila memerlukan pelayanan rehabilitasi medik. Responden yang menyatakan bahwa yang pertama kali terlintas di benak mereka apabila memerlukan pelayanan rehabilitasi medik adalah Rumah Sakit Baptis Batu ada sebanyak 90\%, sedangkan sisanya adalah Rumah Sakit Syaiful Anwar Malang. Alasan responden memilih unit rehabilitasi medik RSBB 50\% karena pelayanan yang baik, cepat dan memuaskan. Alasan lain adalah karena lokasi dekat, melayani askes dan atas anjuran dokter.

Competitor positioning unit rehabilitasi medik RSBB dapat dilihat melalui identifikasi pemanfaatan pelayanan rehabilitasi medik selain di RSBB, dan mengetahui aspek unggulan kompetitor. Responden yang menyatakan pernah memanfaatkan pelayanan unit rehabilitasi medik selain di RSBB ada sebanyak 50\%, yaitu ke RSSA, RS Panti Waluyo Malang, RS Panti Nirmala Malang, RS Paru Batu, RS dr. Sutomo Surabaya. Adapun faktor yang menjadi alasan responden dalam menentukan pilihan untuk menentukan unit rehabitasi medik yang akan melayani mereka adalah pelayanan dan kualitas yang ditawarkan unit rehabilitasi medik terkait. Menurut responden keunggulan unit rehabilitasi medik RSBB dibandingkan dengan unit rehabilitasi medik di RS lain yang pernah mereka manfaatkan adalah jarak yang dekat, pelayanan yang baik, ramah, tepat dan berkualitas, serta memiliki fasilitas yang lengkap (83\%). Responden lainnya (17\%) memberi saran untuk dilakukan penambahan fasilitas, penambahan petugas atauterapist di unit rehabilitasi medik RSBB.

\section{DISKUSI}

Pelayanan unit rehabilitasi medik di RSBB sudah berjalan selama 8 tahun, terhitung mulai tahun 2005. Dalam perkembangannya dari tahun ke tahun menunjukkan perkembangan yang positif, dengan pertumbuhan ratarata $8 \%$ per tahun. Dari hasil survei lapangan, diketahui bahwa di kawasan Batu dan sekitarnya belum ada rumah sakit yang menyediakan fasilitas rehabilitasi medik selengkap RSBB. Kebutuhan akan pelayanan rehabilitasi medik juga meningkat dari tahun ke tahun, bersamaan dengan bertambahnya jumlah pasien yang bisa diselamatkan dari luka yang fatal akibat trauma, maupun penyakit yang parah (5). Dengan tidak adanya pesaing diharapkan RSBB dapat menjadi jujugan serta rujukan pasien-pasien yang membutuhkan perawatan rehabilitasi medik, yang pada akhirnya rehabilitasi medik diharapkan akan menjadi centre of excellence RSBB.

Untuk mewujudkan hal itu, manajemen rumah sakit harus bekerja lebih kreatif dan inovatif untuk menarik hati pelanggan agar mau menggunakan fasilitas unit 
rehabilitasi medik RSBB. Kebutuhan yang sangat utama bagi pemasaran setiap unit di rumah sakit adalah ketertarikan pelanggan. Ketertarikan pelanggan merupakan modal utama yang harus dikelola dengan baik sehingga akan menimbulkan loyalitas pelanggan yang baik pula. Rumah sakit akan mendapatkan manfaat dari loyalitas pemakai jasa rumah sakit, apalagi bila pasien mau menceritakan pengalamannya selama di rumah sakit tersebut kepada pihak lain (word ofmouth) (6). Pasien saat ini mempunyai pengetahuan lebih luas, lebih menuntut dan lebih tidak dapat mentolerir suatu kesalahan dalam pelayanan yang mereka terima. Jadi rumah sakit harus meningkatkan kualitas pelayanan yang diberikan, termasuk pelayanan rehabilitasi medik (5).

Penelitian yang dilakukan menunjukkan bahwa karakteristik responden pada hasil penelitian menggambarkan pengguna layanan rehabilitasi medik terbanyak pada rentang usia 31-55, yang merupakan masa-masa produktif seseorang, sehingga setiap gangguan kesehatan akan menghambat seseorang dalam mencari nafkah dan beraktifitas. Perkembangan dunia kedokteran yang begitu pesat tidak hanya membuat angka harapan hidup meningkat, tetapi juga ikut meningkatkan prevalensi angka kecacatan, misalnya pada pasien stroke (7). Pada saat ilmu kedokteran belum maju, kebanyakan pasien stroke berakhir dengan kematian. Dengan berkembangnya ilmu kedokteran, banyak pasien stroke yang dapat diselamatkan, dengan segala gejala sisa yang ada, yang memerlukan perawatan rehabilitasi medik untuk mengatasinya. Tidak banyak orang yang ingin dirawat di fasilitas rehabilitasi medik, sehingga dalam pemasarannya, unit rehabilitasi medik sangat tergantung pada dokter dan lembaga kesehatan yang akan merujuk pasien mereka untuk menggunakan fasilitas unit rehabilitasi medik (7).

Segmentasi pasar dari unit rehabiltasi medik RSBB dapat dilihat bahwa pengguna layanan terbesar berasal dari Batu sendiri. Adanya pengguna layanan yang berasal dari Malang menunjukkan bahwa segmen pasar sudah meluas keluar wilayah Batu. Dari tingkat pendidikan segmen pasar yang terbanyak menggunakan fasiltas ini adalah sarjana. Hal ini menunjukkan bahwa tingginya tingkat pendidikan seseorang akan mempengaruhi kesadaran seseorang untuk mencari alternatif terapi yang lebih rasional. Dari segi pekerjaan, yang paling banyak adalah pegawai negeri sipil dan pensiunan pegawai negeri sipil, dimana hal ini juga berhubungan langsung dengan sumber pembiayaan responden.

Sumber pembiayaan terbesar adalah dari asuransi kesehatan PT ASKES. Melihat kenyataan ini, dapat dilihat bahwa pemasaran ke pasien yang membayar mandiri masih perlu ditingkatkan. Tetapi di era Jaminan Kesehatan Nasional (JKN) seperti sekarang ini, penekanan pada target pasar pasien yang membayar mandiri perlu dipertimbangkan lagi, sebab JKN menggunakan sistem asuransi, dimana nantinya seluruh warga negara Indonesia wajib menyisihkan sebagian kecil uangnya untuk jaminan kesehatan di masa depan. Sebagai penyelenggara JKN ditunjuk Badan Penyelenggara Jaminan Kesehatan (BPJS). Sumber pembiayaan semua peserta JKN yang menggunakan fasilitas rehabilitasi medik adalah BPJS.

Identifikasi implementasi positioning unit rehabilitasi medik RSBB, bertujuan untuk menjelaskan suatu kesan atau ciri khas yang paling melekat di pikiran responden tentang unit rehabilitasi medik RSBB (9). Kepuasan pasien memegang peranan penting dalam bidang rehabilitasi medik, sehingga dapat dijadikan sebagai indikator dan tolok ukur dalam menentukan keunggulan terapi dan pelayanan yang diberikan (10). Untuk dapat menarik pasien diperlukan usaha pemasaran yang lebih befokus pada fasilitas dan tingkat keberhasilan pelayanan. Fasilitas yang ditawarkan harus berkualitas tinggi, dengan tingkat keberhasilan yang tinggi pula (11). Responden memberi kesan bahwa unit rehabilitasi medik RSBB sudah memberikan pelayanan yang baik, ramah, cepat, tepat, serta mempunyai tingkat keberhasilan terapi yang baik, dengan fasilitas lengkap dan harga yang terjangkau.

Unit rehabilitasi medik RSBB merupakan rumah sakit yang pertama kali terlintas di benak responden apabila memerlukan pelayanan rehabilitasi medik. Hanya $10 \%$ yang memikirkan rumah sakit lain, yaitu RSSA Malang. Hal ini menunjukkan bahwa unit rehabilitasi medik RSBB sudah menjadi top of mind responden dalam pemilihan pelayanan rehabilitasi medik. Alasan mereka dalam memilih unit rehabilitasi medik RSBB adalah karena pelayanannya yang baik, cepat, memuaskan, lokasi dekat, melayani askes dan atas anjuran dokter.

Menurut responden keunggulan unit rehabilitasi medik RSBB dibandingkan dengan unit rehabilitasi medik di RS lain yang pernah mereka manfaatkan adalah jarak yang dekat, pelayanan yang baik, ramah, tepat dan berkualitas, serta memiliki fasilitas yang lengkap. Ada juga responden memberi saran untuk dilakukan penambahan fasilitas, penambahan petugas atau terapis di unit rehabilitasi medik RSBB.

Petugas yang melayani unit rehabilitasi medik RSBB terdiri dari 1 orang dokter spesialis kedokteran fisik dan rehabilitasi, 2 orang terapis, 1 orang terapis okupasi yang merangkap sebagai petugas administrasi, 2 orang asisten terapis. Dokter spesialis tersebut, mulai tahun 2009 merangkap menjadi direktur RSBB, sehingga pelayanan di unit rehabilitasi medik tidak bisa optimal, mengingat kesibukannya sebagai direktur.

Unit rehabilitasi medik melayani pasien mulai jam 7 pagi sampai jam 3 siang, dengan jumlah kunjungan rata-rata per hari 40, yang terdiri dari 30 kunjungan pasien luar, 10 kunjungan pasien rawat inap RSBB. Setiap pelayanan pasien memerlukan waktu lebih kurang 30 menit. Waktu yang diperlukan untuk melayani semua pasien adalah 20 jam perhari. Dengan jumlah terapis yang hanya 2 orang, maka untuk dapat melayani semua pasien setiap terapis harus bekerja selama $10 \mathrm{jam}$, sedangkan waktu pelayanan yang tersedia adalah 8 jam perhari. Pada prakteknya para terapis melayani beberapa pasien pada saat yang bersamaan terutama pasien-pasien yang perlu penanganan dengan alat bantu. Hal ini menyebakan terapis tersebut berpindah-pindah dari satu pasien ke pasien yang lain. Dalam hal ini peran asisten terapis yang ada sangat membantu meringankan beban kerja terapis. Begitu juga dengan jumlah alat dan fasilitas yang ada. Dengan semakin bertambahnya jumlah pasien, maka jumlah alat yang disediakan juga harus mencukupi kebutuhan, untuk menghindari waktu tunggu yang panjang.

Dari rata-rata 40 kunjungan per hari tersebut, hanya $5 \%$ yang menggunakan pelayanan terapi okupasi. Hal ini 
menunjukkan pemasaran untuk terapi okupasi belum berhasil. Saat ini yang menggunakan pelayanan terapi okupasi hanya pasien-pasien pasca stroke saja, padahal masih banyak sasaran pemasaran yang bisa menggunakan terapi okupasi ini, misalnya terapi untuk anak autis, anak yang mengalami cerebral palsy.

Hasil penelitian ini menunjukkan bahwa pelayanan

\section{DAFTAR PUSTAKA}

1. Aditama TY. Manajemen Administrasi Rumah Sakit. Jakarta: UI-Press; 2006.

2. Rumah Sakit Baptis Batu. Rencana Strategis RS Baptis Batu. Batu: RS Baptis Batu; 2013.

3. Howland C, Halstead L, and Grabois M. Medical Rehabilitation. New York: Raven Press; 1985.

4. Nwaka S, Ochem A, Besson D, et al. Analysis of PanAfrican Centres of Excellence in Health Innovation Highlights Opportunities and Challenges for Local Innovation and Financing in the Continent. BMC International Health and Human Rights. 2012; 12(11): 12.

5. Einspruch EM, Omachonu VK, and Einspruch NG. Quality Function Deployment (QFD): Application to Rehabilitation Services. International Journal of Health Care Quality Assurance. 1996; 9(3): 42-46.

6. Trarintya MAP. Pengaruh Kualitas Pelayanan Terhadap Kepuasan dan Word of Mouth (Studi Kasus rehabilitasi medik di RSBB sudah menempati posisi dan kesan yang positif di mata pelanggan yang masih banyak dipengaruhi karena faktor akses baik jarak maupun biaya disamping mutu pelayanan. Penguatan dalam pemasaran dan mutu pelayanan yang didukung sumberdaya manusia yang adekuat menjadi syarat pengembangan unit rehabilitasi medik sebagai center of excellence di RSBB.

Pasien Rawat Jalan di Wing Amerta RSUP Sanglah Denpasar). [Tesis]. Universitas Udayana, Denpasar. 2011.

7. Wheatley B, DeJong G, and Sutton J. Consolidation of the Inpatient Medical Rehabilitation Industry. Health Affairs. 1998; 17(3): 209-215.

8. Chandra A, Stroube WB, and Plitt JH. Itemization of Rehabilitation Centers from Marketing Point of ViewCurrent Analysis and Future Challenges. (Online) 2002. http://sbaer.uca.edu/research/acme/2002/21.pdf

9. Kartajaya H, Yuswohady, Mussry J, dan Taufik. Positioning, Diferensiasi, dan Brand. Jakarta: PT. Gramedia Pustaka; 2008.

10. Bergés I, Ottenbacher KJ, Smith PM, Smith D, and Ostir GV. Perceived Pain and Satisfaction with Medical Rehabilitation after Hospital Discharge. Clinical Rehabilitation. 2006; 20(8): 724-730.

11. Frisch J and McNamara J. Optimizing the Performance of a Hospital Outpatient Rehabilitation Department. Louisville: RehabCare; 2012. 